\title{
DOES THE CROWN COURT DISCRIMINATE AGAINST MUSLIM- NAMED OFFENDERS? A NOVEL INVESTIGATION BASED ON TEXT MINING TECHNIQUES
}

\author{
Jose Pina-Sánchez*, Julian V. Roberts and Dimitrios Sferopoulos
}

Most research in sentencing discrimination in the United Kingdom has relied on aggregate analyses comparing disparities by ethnic group. These studies fail to consider differences in the individual characteristics of the cases processed. To circumvent the lack of official data, we scraped sentence records stored in a commercial website, from which a sample of 8,437 offenders sentenced to custody in the Crown Court from 2007 to 2017 was generated. Using the names of the offenders, we have been able to classify 8.6 per cent of our sample as having a traditional Muslim name. We find that Muslim-named offenders received sentences 9.8 per cent longer than the rest of the sample. However, this difference disappeared once we accounted for the type of offence and other key case characteristics.

Key Words: sentencing, discrimination, Muslim, Crown Court, data scraping

\section{Introduction}

Is there evidence of discrimination at sentencing in England and Wales? The 2017 Lammy Review has provided a timely reminder of the need for more-and betterresearch into the criminal justice treatment of racial, ethnic and immigrant minorities in England and Wales. A significant body of research addresses the differential impact on these groups at all stages of the criminal process (e.g. Chigwada-Bailey 2003; Hood et al. 2003; Cole and Wardak 2006; Earle 2011; Phillips 2012; Phillips and Bowling 2017; Irwin-Rogers 2018). Sentencing-the most visible and symbolic stage of that process (Ashworth 2010) - has been subject to far less academic scrutiny. The most significant study of race and sentencing is now over a generation old (Hood 1992). Since then, empirical research has been intermittent, ${ }^{1}$ with the Ministry of Justice undertaking much of the work on this topic. As part of its section 95 duties, the Ministry of Justice publishes annual statistics relating to race and criminal justice, including sentencing (e.g. Ministry of Justice 2017). These reports provide bivariate statistics, highlighting relationships between race and sentencing outcomes, but are unable to control for relevant case characteristics that might explain those relationships.

The Lammy Review demonstrated racial disparities in sentencing outcomes for certain offence categories. More specifically, the review reported that within drug offences

*Jose Pina-Sánchez, School of Law, University of Leeds, The Liberty Building, Leeds LS2 9JT, UK; j.pinasanchez@leeds.ac.uk; Julian V. Roberts, Faculty of Law, University of Oxford, Oxford, UK; Dimitrios Sferopoulos, Independent Researcher.

${ }^{1}$ Feilzer and Hood (2004) and May et al. (2010) represent the two most important contributions following Hood (1992), although their focus is limited to young offenders. 
the odds of a prison sentence were 240 per cent higher for defendants who self-identify as Black, Asian or Minority Ethnic (BAME) compared with White defendants. The review's analysis took some relevant case characteristics into account. For example, previous convictions and plea were considered, but not other mitigating or aggravating circumstances or indeed the possibility that BAME drug offenders had been convicted of more serious drug crimes (see Hopkins et al. 2016; Lammy 2017: 33). Regrettably, the Lammy Review failed to conduct or commission original empirical research, which might have accounted for other relevant case characteristics. Nor did the review draw upon existing databases that could have helped answering the key question of whether and to what extent racial minorities are treated differently.

The Ministry of Justice biennial report 'Statistics on Race and the Criminal Justice System' has consistently documented sentencing differentials between BAME defendants and White defendants accused of the same offence. The most recent Ministry report (2017) found that BAME defendants had a higher custody rate than White defendants. In addition, since 2012, the average sentence length has been consistently longer for all non-White ethnic groups. In 2016, of all offenders sentenced to immediate custody, Black and Asian offenders received an average sentence length of 24 and 25 months, respectively, compared with 18 months for White offenders (Ministry of Justice 2017: 53). These disparities are cause for concern (see The Secret Barrister 2018: 285). However, they do not constitute incontrovertible evidence of discrimination at the sentencing stage since we do not know whether the differential outcomes can be explained by legally relevant factors ${ }^{2}$ (Green 1961; Hall and Simkus 1975; Raynor and Lewis 2011; Pina-Sánchez and Linacre 2016) such as those determining the harm of the offence or the culpability of the offender. If for example, BAME defendants were less likely to plead guilty —as suggested by Thomas (2010) and Hood (1992)—we would expect to see differences in sentencing outcomes, all other characteristics being equal.

This methodological challenge is not new. In 1987, Zatz described the comparison of group means as an obsolete approach to investigate sentence disparities. Multivariate approaches are superior when it comes to detecting the presence of discrimination in sentencing. These methods can be used to control simultaneously for the relevant aggravating and mitigating factors present in different cases, which is key to be able to distinguish legitimate disparities in sentencing from truly discriminatory practices. Hundreds of such studies have been conducted in the United States, with regression modelling being the predominant method of choice (Baumer 2013). In the United Kingdom, however, official sentencing data have traditionally been presented in an aggregated format, precluding the use of regression modelling techniques. In response to critics, ${ }^{3}$ the Ministry of Justice released a large data set of 1.2 million cases sentenced from 2007 to 2011 at the magistrates and Crown Courts. ${ }^{4}$ These individual cases included some important demographic characteristics of the defendant, such as age, gender and ethnic group; however, they did not contain any relevant case characteristics other than the broad offence type, thus preventing researchers from differentiating between warranted and unwarranted disparities.

\footnotetext{
${ }^{2}$ It is worth noting that the unequal distribution of these factors across ethnic groups could be due to discriminatory process within the criminal justice process that precedes the sentencing stage. This article, however, is specifically limited to the detection of potential discriminatory practices at sentencing, rather than discrimination across the whole justice system.

${ }^{3}$ See Peter Herbert, chairman of the Society of Black Lawyers interview for The Independent, http://www.independent.co.uk/ news/uk/crime/courts-are-biased-against-blacks-with-white-offenders-less-likely-to-be-jailed-for-similar-crimes-8959804.html. ${ }^{4}$ See https://www.theguardian.com/law/2011/nov/25/open-justice-court-data.
} 
PINA-SÁNCHEZ ET AL.

\section{Muslim defendants}

The focus of almost all quantitative research on race and sentencing in England and Wales to date has been upon the principal ethnic category. Individuals self-define their ethnicity using categories derived from the 2001 Census, namely 'White', 'Mixed', 'Asian', 'Black', and 'Chinese' or 'Other'. However, these are not the only minority groups who may be subject to discrimination. In the current climate created by the recent terrorist attacks, some have expressed the view that the courts may sentence Muslim offenders more harshly. Scholars have argued that 'Muslims have replaced the Irish as the main focus of the government's security agenda', and this may have created an adverse climate for defendants perceived to be Muslim (see Pantazis and Pemberton 2009: 646). The Independent Reviewer of Terrorism Legislation in the United Kingdom noted in his 2011 annual report that: 'Some Muslims believe that there is a greater readiness on the part of press, politicians, police and law enforcement officers to characterise attacks by Muslims as "terrorism" than attacks by far-right extremists. This, they say, results in discriminatory sentencing and cements popular perceptions of terrorism, at least in Great Britain, as crime perpetrated overwhelmingly by Muslims' (Anderson 2012: 26).

In 2013, the government released sentencing statistics for terrorism offences broken down by the (self-classified) religion of the offender. The statistics revealed that average sentence lengths were longer for Muslim offenders (8.3 years) than for other offenders (6.9 years); yet, given the small sample size used (220 offenders), this difference was not statistically significant (Home Office 2013). In addition, the analyses did not control for important case characteristics, which could have explained this discrepancy, and the sample was drawn from the period 2001-12. Concern over the possibility of discriminatory sentencing has become more intense since 2012, in the wake of additional terrorist attacks perpetrated by Muslim extremists.

Exploring in any further detail the presence of discrimination against Muslims or other minorities has been seriously limited given the unavailability of official individual-level sentencing data capturing any basic information regarding the ethnicity of the defendant and the characteristics of the case. Normally, the options available to researchers involve the collection of primary data through methods such as court observation (Brown and Hullin 1992) or file review (Hood 1992), both of them expensive and time-consuming undertakings. However, there is a third way: defendants can be classified into certain minority groups based on the defendants' names extracted from court records using text mining techniques. Names perceived to be associated with particular ethnic identities may trigger a discriminatory response from actors in the criminal justice system. This study reports original analyses conducted on a new sentencing database to explore whether offenders with traditional Muslim names attract a different sentence, and if so, whether any noted differences can be attributed to discriminatory sentencing practices.

\section{Analytical strategy}

To circumvent the limitations in the official sentence data from England and Wales, we explored an alternative and original research approach: we accessed, parsed and analysed sentence transcripts uploaded online at www.thelawpages.com. For decades, legal 
practitioners have used a variety of web databases to access sentencing judgements (e.g. BAILII or Westlaw), normally passed in high or appellate courts. More recently, www. thelawpages.com, a commercial website used as a hub for legal practitioners to advertise their services, has made available summaries of sentence transcripts of offences sentenced in the Crown Court. Fortuitously, for researchers, these records capture a great deal of information relating to sentence outcomes (the disposal type, sentence length and whether the sentence is indeterminate), characteristics of the case (e.g. whether the offender was granted bail or entered a guilty plea), the court and the judge who imposed the offence and some offender characteristics (e.g. gender and name).

'The Law Pages' data seem to derive from Her Majesty Courts and Tribunals Service (HMCTS). This can be deduced from one important detail, the 'Case Number', a unique identifier used by HMCTS for the internal management of trials. ${ }^{5}$ The same identifier can be found in each of the records of 'The Law Pages', indicating that records have been accessed directly from HMCTS. Further evidence of the validity of the data emerges from the academic research (Lavorgna 2015; Jacobson et al. 2016) citing cases accessed from this source. So far, the legal and academic research using this data have involved the analysis of very specific types of cases. For example, Jacobson et al. (2016) used records from 'The Law Pages' to boost their sample of cases featuring multiple offences. A large-scale quantitative study such as the one presented here has yet to be carried out.

\section{Data scraping and text mining}

We used data scraping techniques to download the entire archive of records from 'The Law Pages' available in August 2017. Specifically, we designed a data scraping algorithm using Perl and Selenium based on the sequential pattern in the URL available for each individual record ${ }^{6}$ We created a large data set of 18,220 cases $^{7}$ sentenced in the Crown Court between 2007 and 2017. Once downloaded, all records were individually parsed to search for specific keywords, from which relevant variables could be retrieved. Most variables in our data set were taken directly from the transcripts (e.g., type of offence, or the offender's gender); others such as whether the sentence was indeterminate or, crucially, whether the offender carried a traditional Muslim name were derived at a second stage using matching techniques.

Following this 'text mining' of 'The Law Pages' records, we were able to code 47 caserelevant variables. These include three key sentence outcomes: (1) whether custody was imposed, (2) the number of months of the imprisonment and (3) whether the custodial sentence was determinate or indeterminate. The defendant characteristics include gender and whether Muslim-named or not. Other relevant case characteristics retrieved include the presence of co-defendants, any multiple convictions, multiple counts of the same offence, plea, whether mitigating factors were recorded, whether a public

\footnotetext{
${ }^{5}$ See http://xhibit.justice.gov.uk.

${ }^{6}$ This research is protected by the 2014 amendments to the 1988 Copyrights, Designs and Patents Act. One of those amendments made legal the 'mining' of online data available to the public if the data is to be used for research and not commercial purposes.

${ }^{7}$ The archive of sentence records available at 'The Law Pages' is updated on a daily basis shortly after sentences are imposed, consequently the size of their archive has grown since we accessed it in late 2017.
} 
protection sentence was imposed, the existence of a victim personal statement, whether the victim sustained injuries and whether the defendant had been remanded in detention pre-trial. Last, we were able to differentiate between 36 specific offence types. The possibility of using such specific offence types as opposed to the broad offence categories employed in the Ministry reports and most of the literature on sentencing discrimination (see Everett and Wojtkiewicz 2002; Feldmeyer and Ulmer 2011; Fischman and Schanzenbach 2012) is crucial in order to control for the seriousness of the offence.

The mean and range of the variables we were able to code are shown in Table 1. Except for the number of months of the imprisonment, all the variables included are binary. As such, the means shown in Table 1 can be used to assess the prevalence of each case characteristic in our study. For example, the offence 'Inflicting grievous bodily harm' has a value of 0.026 indicating that this offence type accounts for 2.6 per cent of the cases in our sample. Similarly, the aggravating factor 'Victim sustained injuries' had a value of 0.185 , which indicates that this factor features in 18.5 per cent of the cases in our sample.

The data presented in Table 1-and analysed in the next section-represent a subsample of 8,437 violent and sexual offenders sentenced to immediate custody in the Crown Court from 2007 to 2017. The violent and sexual offences considered represent the more common offences recorded in the data stored at 'The Law Pages'. Most of other broad groups of offences such as drugs, theft, burglary or fraud offences are subdivided into specific offence types featuring only a few cases in 'The Law Pages' data. Controlling for such cases in a statistical model would involve the inclusion of a large number of additional covariates, which risks overfitting the model and encountering problems of multicollinearity. In addition, the possibility of omitted relevant variables bias is always present in non-experimental quantitative sentencing research since capturing the full list of relevant case characteristics is well-nigh impossible (Brantingham 1985; Waldfogel 1998; Anderson et al. 1999; Hofer et al. 1999; Baumer 2013; PinaSánchez and Linacre 2013; 2014). Given the relatively modest number of case characteristics-other than the offence type-that we managed to extract from the transcripts, ${ }^{8}$ we decided to focus on a more homogeneous group of offences, and in so doing, sacrifice some precision for greater accuracy in our estimates. For example, whether the victim sustained injuries-one of the factors captured-seems more relevant to violent and sex offences than to say drugs offences. Similarly, whether the offence committed reported a high gain-a case characteristic that we could not capture-would be more relevant to theft or burglary offences.

Although no information on the sampling strategy employed by 'The Law Pages' was available, information about the generalizability of our sample can be obtained from the location of the court where the sentence was passed. We observe a good geographical spread across the Crown Court locations, although the Central Criminal Court is over-represented (accounting for 9 per cent of the sample, whereas the mean and median percentage of cases seen across the 86 courts in our sample is 1.2 and 0.8 per cent). The higher concentration of cases from the Old Bailey is likely a reflection of the overrepresentation of serious offences in our sample. In fact, the four most common

\footnotetext{
${ }^{8}$ Compared with recent research undertaken in England and Wales employing the Crown Court Sentencing Survey; see e.g. Belton (2018), Irwin-Rogers and Perry (2015), Lightowlers and Pina-Sánchez (2017) or Lightowlers (2018).
} 
TABLE 1 Descriptive statistics of the variables captured in our sample

\begin{tabular}{|c|c|c|c|}
\hline Variable & Mean & Minimum & Maximum \\
\hline \multicolumn{4}{|l|}{ Response variable } \\
\hline Sentence length (in months) & 123 & 1 & 540 \\
\hline Life or indeterminate sentence & 0.256 & 0 & 1 \\
\hline \multicolumn{4}{|l|}{ Offender characteristics } \\
\hline Offender male & 0.934 & 0 & 1 \\
\hline Offender Muslim-name & 0.086 & 0 & 1 \\
\hline \multicolumn{4}{|l|}{ Case characteristics } \\
\hline Co-defendants & 0.369 & 0 & 1 \\
\hline Public protection sentence & 0.292 & 0 & 1 \\
\hline Guilty plea entered & 0.499 & 0 & 1 \\
\hline Mitigating factors & 0.092 & 0 & 1 \\
\hline On remand & 0.377 & 0 & 1 \\
\hline Sentenced for a different second offence & 0.380 & 0 & 1 \\
\hline Sentenced for a different third offence & 0.150 & 0 & 1 \\
\hline Sentenced for a different fourth offence & 0.060 & 0 & 1 \\
\hline Sentenced for more than four different offences & 0.024 & 0 & 1 \\
\hline Multiple counts of the same offence & 1.554 & 0 & 1 \\
\hline Victim impact statement & 0.252 & 0 & 1 \\
\hline Victim sustained injuries & 0.185 & 0 & 1 \\
\hline \multicolumn{4}{|l|}{ Principal offence (reference category: murder) } \\
\hline Assault occasioning actual bodily harm & 0.075 & 0 & 1 \\
\hline Inflicting grievous bodily harm & 0.026 & 0 & 1 \\
\hline Conspiracy to commit grievous bodily harm & 0.004 & 0 & 1 \\
\hline Causing grievous bodily harm with intent & 0.096 & 0 & 1 \\
\hline Causing an affray & 0.016 & 0 & 1 \\
\hline Violent disorder & 0.021 & 0 & 1 \\
\hline Unlawful (malicious) wounding & 0.013 & 0 & 1 \\
\hline Common assault/assault by beating & 0.004 & 0 & 1 \\
\hline Murder & 0.221 & 0 & 1 \\
\hline Attempted murder & 0.034 & 0 & 1 \\
\hline Manslaughter & 0.080 & 0 & 1 \\
\hline Arson & 0.004 & 0 & 1 \\
\hline Arson reckless/with intent to endanger life & 0.010 & 0 & 1 \\
\hline Conspiracy to commit arson & 0.001 & 0 & 1 \\
\hline Robbery & 0.051 & 0 & 1 \\
\hline Attempted robbery & 0.009 & 0 & 1 \\
\hline Conspiracy to commit robbery & 0.018 & 0 & 1 \\
\hline Rape & 0.071 & 0 & 1 \\
\hline Indecent assault & 0.027 & 0 & 1 \\
\hline Indecent assault of a child & 0.004 & 0 & 1 \\
\hline Sexual activity with a child & 0.035 & 0 & 1 \\
\hline Sexual assault & 0.018 & 0 & 1 \\
\hline Rape of a child & 0.014 & 0 & 1 \\
\hline Attempted rape & 0.003 & 0 & 1 \\
\hline Attempted rape of a child & 0.002 & 0 & 1 \\
\hline Assault by penetration & 0.002 & 0 & 1 \\
\hline Dangerous driving & 0.019 & 0 & 1 \\
\hline Causing death by careless driving & 0.008 & 0 & 1 \\
\hline Causing death by dangerous driving & 0.036 & 0 & 1 \\
\hline Causing death by careless driving while over the alcohol limit & 0.005 & 0 & 1 \\
\hline Causing serious injury by dangerous driving & 0.003 & 0 & 1 \\
\hline Kidnap & 0.010 & 0 & 1 \\
\hline Conspiracy to kidnap & 0.002 & 0 & 1 \\
\hline Restraint of person's freedom of movement & 0.018 & 0 & 1 \\
\hline
\end{tabular}


PINA-SÁNCHEZ ET AL.

TABLE 1 Continued

\begin{tabular}{|c|c|c|c|}
\hline Variable & Mean & Minimum & Maximum \\
\hline Collecting a record of information to commit acts of terrorism & 0.005 & 0 & 1 \\
\hline Engaging in conduct in preparation for acts of terrorism & 0.008 & 0 & 1 \\
\hline \multicolumn{4}{|l|}{ Sample size } \\
\hline \multicolumn{4}{|l|}{ Level 1-case: $N=8,437$} \\
\hline Level 2-court: $N=86$ & & & \\
\hline
\end{tabular}

offences captured are murder, GBH with intent, $\mathrm{ABH}$ and rape (comprising 22.1, 9.6, 7.5 and 7.1 per cent of the sample).

\section{Identifying 'traditional Muslim’ names}

In the absence of self-reported or register data on the offender's ethnic identity or religious affiliation, we employed a name-based estimation process. The estimation of ethnic membership belonging based on names is a common approach in the field of epidemiology (see Cummins et al. 1999; Nanchahal et al. 2001; Bouwhuis and Moll 2003), but has only recently been adopted in criminology (see King and Johnson 2016). This approach will inevitably generate some degree of misclassification. For example, Mateos (2007: 255) identifies common problems of misclassification derived from issues such as 'name normalization' ('different transcriptions of a name into a different language's alphabet and/or pronunciation [...] creating name duplications and long lists of name variants'), or the fact that names usually only reflect patrilineal heritage. However, in his review of the literature, the author also notes the remarkable levels of sensitivity (proportion of subjects from the target ethnic group correctly classified) and specificity (proportion of subjects that do not belong to the target ethnic group correctly classified as such) obtained in the studies reviewed (ranging from 0.67 to 0.95 and from 0.80 to 1 , respectively). Furthermore, it is important to note that in the context of discrimination in sentencing, self-identified reports of ethnicity can be equally problematic, ${ }^{9}$ since the discriminatory mechanism will be triggered by the judge's-not the defendant's-perceptions.

We matched the offenders' first name, middle name and surname/s, against a list of traditional Muslim names obtained from www.alquranic.com, which contains 1,880 different female names and 1,643 male names. This initial matching process classified 677 offenders (8 per cent of our sample) as Muslim-named. In order to assess the quality of the estimation process, we manually reviewed the names of offenders classified as Muslim-named and the remaining 7,760 offenders in our sample. Two problems became apparent following this review: (1) inconsistencies resulting from the previously noted issue of 'name normalization' (e.g. the list of names from 'Alquranic' only contemplates one spelling of the prophet's name 'Mohammed', whereas in our sample from 'The Law Pages', we identified four additional spelling variations, 'Mohamed', 'Mohammad', 'Muhammed', 'Muhamed') and (2) certain names included in the 'Alquranic' list are also widely used by non-Muslims (e.g. 'Daniel', 'Adam', 'Natasha' or 'Sarah').

${ }^{9}$ See Saperstein (2006) for an analysis of the limitations of self-reported ethnicity. 
Since in the context of our study, false positives (subjects wrongly identified as Muslimnamed) can be deemed more problematic ${ }^{10}$ than false negatives (subjects wrongly identified as non-Muslim-named), names that would not normally be associated to Muslims were removed from the list of Muslim names. In addition, the spelling of Muslim-names registered in 'The Law Pages' under a different spelling to that in 'alquranic' were harmonized. A second matching process after having taken into account the two issues identified provided a total of 722 offenders classified as Muslim-named (8.6 per cent of our sample). We do not have access to a 'gold standard' to quantify the degree of misclassification in our 'Muslim-name' estimate. However, the qualitative approach undertaken to supervise the matching process points at a high level of accuracy. The vast majority of offenders classified as Muslim-named would normally be identified as such in the context of the United Kingdom, and the same applies to those classified as non-Muslim-named. ${ }^{11}$

Despite these validity checks, it would be naive to believe that our Muslim-named variable is unaffected by misclassification. It is worth reiterating, however, that judges themselves do not necessarily know whether the defendant is Muslim or not. They would infer this characteristic from visual cues (e.g. skin colour or clothing) or from the defendant's name. This last point is important. Regardless of the problems affecting name-based ethnic classifications and regardless of whether the defendant is actually Muslim, what matters is whether the judge perceives-consciously or subconsciouslythem as Muslim.

\section{Statistical analysis: testing for name-based sentencing differentials}

Our analysis is based on the comparison of custodial sentence lengths for Muslimnamed and all other offenders, which we undertake in two stages. The first stage involves the comparison of the average sentence length for each of the two groups, followed by a $t$-test to ascertain whether any observed differences are statistically significant. This is the type of analysis that we could perform to investigate discrimination against BAME based on the official data currently available to researchers in the United Kingdom. This approach, however, is only capable of establishing gross disparities. That is, disparities that could be due to discriminatory practices, conflated with legitimate disparities reflecting differences in the legally relevant characteristics of the cases processed.

To test for unwarranted (or net) disparities, in the second stage of our analysis, we specify a statistical model controlling for all the case characteristics derived from the 'The Law Pages' records. To account for the typical deviation from normality commonly observed in distributions of custodial sentence length and for the presence of indeterminate and life imprisonment sentences, an event history model ${ }^{12}$ is employed. We used a proportional hazards Cox model (Cox 1975) since its estimation process is based on partial likelihood. As such, no parametric assumptions are imposed on the baseline hazard function of the model, which removes the requirement to transform the variable custodial sentence length to make it normally distributed (Bushway and

\footnotetext{
${ }^{10}$ This is because the smaller proportion of Muslim offenders than non-Muslim offenders captured in our sample.

${ }^{11}$ To respect the confidentiality of the offenders, we have decided not to publish any full names, but we can provide this information upon request.

${ }^{12}$ Also known as survival or time-to-event models.
} 
Piehl 2001; Johnson 2005; Pina-Sánchez and Linacre 2013). In addition, this model allows us to specify indeterminate sentences adequately as right-censored durations, since we know the minimum tariff that the offender will have to serve in prison, but we do not know whether that duration could be extended given the indeterminate nature of the sentence.

The set of covariates include Muslim-name and the gender of the offender, together with relevant case characteristics. The reference case against which specific offence types are to be compared is murder. Given the proportional hazards specification of our model, the regression coefficients obtained for each of the covariates included should be understood as the effect of each of those variables on the hazard rate (i.e. representing the 'risk' of prison terms to be terminated at a specific point in time). Hence, negative coefficients will be associated with the imposition of longer sentences, while positive coefficients will indicate a shorter sentence. Last, given the hierarchical nature of the data, with cases sentenced within courts, a random intercepts component is included. ${ }^{13}$ The model is estimated using $\mathrm{R}$ and the packages 'survival' and 'coxme' (Therneau 2015; 2018).

\section{Results}

The average custodial sentence length for offenders with traditional Muslim names was 134 months, while that of the non-Muslim-named group was 122 months. Thus, Muslim-named offenders received on average sentences 9.8 per cent longer than other offenders, a difference that is statistically significant (Welch two-sample $t$-test, $P$ value $<0.003$ ). If no case characteristics had been available to us, this would have been the end of the analysis; we would have been unable to determine whether the more severe treatment of Muslim-named offenders was due to differences in the offences committed or to sentencing discrimination. However, the presence of certain case characteristics in the database permitted us to calculate average sentence lengths conditional on important legally relevant factors. When this approach is undertaken, the Muslim-name effect is no longer statistically significant. Results for the whole model are presented in Table 2 .

It could be argued that the coefficient for Muslim-name being non-significant is due to the small sample used and that if we were to use the whole census of offenders processed in the Crown Court, we might find a significant effect. However, the effect size of Muslim-name is the smallest of all the covariates included, demonstrating its remarkably low substantive importance. To put the effect size of the coefficient for having a traditional Muslim name in context, it is worth comparing it to another personal characteristic like gender, which is statistically significant and approximately eighteen times bigger.

The null effect of Muslim-name is also compelling when we take into account that with the exception of sentenced for more than four different offences and victim sustained injuries, ${ }^{14}$ all factors included in the model were found statistically significant and pointing

\footnotetext{
${ }^{13} \mathrm{Also}$ known in the event history analysis literature as a frailty model.

${ }^{14}$ The association of victim injuries with shorter sentences is probably due to a problem of omitted relevant variables. It is possible that we are not controlling for the variability of murder cases adequately. Murder is the biggest offence group (22.1 per cent of our sample) but it is also an offence that leaves no injuries. Therefore, it is likely that this unobserved variability has been picked up by the regression coefficient for victim injuries.
} 
DOES THE CROWN COURT DISCRIMINATE AGAINST MUSLIM-NAMED OFFENDERS?

TABLE 2 Results from the proportional hazards multilevel Cox model (response variable: custodial sentence length in months)

\begin{tabular}{|c|c|c|c|}
\hline Variable & Coefficient & Standard error & $P$ value \\
\hline \multicolumn{4}{|l|}{ Offender characteristics } \\
\hline Offender male & -0.337 & 0.052 & $<0.001$ \\
\hline Offender Muslim-name & -0.019 & 0.050 & 0.970 \\
\hline \multicolumn{4}{|l|}{ Case characteristics } \\
\hline Co-defendants & -0.191 & 0.031 & $<0.001$ \\
\hline Public protection sentence & -0.756 & 0.045 & $<0.001$ \\
\hline Guilty plea entered & 0.611 & 0.029 & $<0.001$ \\
\hline Mitigating factors & 0.349 & 0.043 & $<0.001$ \\
\hline On remand & -0.537 & 0.033 & $<0.001$ \\
\hline Sentenced for a different second offence & -0.656 & 0.035 & $<0.001$ \\
\hline Sentenced for a different third offence & -0.421 & 0.049 & $<0.001$ \\
\hline Sentenced for a different fourth offence & -0.556 & 0.078 & $<0.001$ \\
\hline Sentenced for more than four different offences & 0.136 & 0.103 & 0.190 \\
\hline Multiple counts of the same offence & -0.094 & 0.009 & $<0.001$ \\
\hline Victim impact statement & -0.253 & 0.032 & $<0.001$ \\
\hline Victim sustained injuries & 0.113 & 0.038 & 0.003 \\
\hline \multicolumn{4}{|l|}{ Principal offence (reference category: murder) } \\
\hline Assault occasioning actual bodily harm & 4.582 & 0.088 & $<0.001$ \\
\hline Inflicting grievous bodily harm & 4.99 & 0.106 & $<0.001$ \\
\hline Conspiracy to commit grievous bodily harm & 3.311 & 0.198 & $<0.001$ \\
\hline Causing grievous bodily harm with intent & 3.207 & 0.083 & $<0.001$ \\
\hline Causing an affray & 5.656 & 0.121 & $<0.001$ \\
\hline Violent disorder & 5.24 & 0.113 & $<0.001$ \\
\hline Unlawful (malicious) wounding & 5.031 & 0.124 & $<0.001$ \\
\hline Common assault/assault by beating & 5.124 & 0.192 & $<0.001$ \\
\hline Attempted murder & 1.821 & 0.107 & $<0.001$ \\
\hline Manslaughter & 3.328 & 0.085 & $<0.001$ \\
\hline Arson & 4.461 & 0.198 & $<0.001$ \\
\hline Arson reckless/with intent to endanger life & 3.754 & 0.135 & $<0.001$ \\
\hline Conspiracy to commit arson & 3.521 & 0.347 & $<0.001$ \\
\hline Robbery & 3.506 & 0.091 & $<0.001$ \\
\hline Attempted robbery & 3.908 & 0.140 & $<0.001$ \\
\hline Conspiracy to commit robbery & 3.067 & 0.115 & $<0.001$ \\
\hline Rape & 3.016 & 0.088 & $<0.001$ \\
\hline Indecent assault & 4.059 & 0.115 & $<0.001$ \\
\hline Indecent assault of a child & 3.752 & 0.188 & $<0.001$ \\
\hline Sexual activity with a child & 3.987 & 0.103 & $<0.001$ \\
\hline Sexual assault & 4.432 & 0.115 & $<0.001$ \\
\hline Rape of a child & 2.802 & 0.127 & $<0.001$ \\
\hline Attempted rape & 3.656 & 0.238 & $<0.001$ \\
\hline Attempted rape of a child & 3.383 & 0.292 & $<0.001$ \\
\hline Assault by penetration & 3.815 & 0.238 & $<0.001$ \\
\hline Dangerous driving & 5.343 & 0.118 & $<0.001$ \\
\hline Causing death by careless driving & 5.35 & 0.150 & $<0.001$ \\
\hline Causing death by dangerous driving & 3.563 & 0.098 & $<0.001$ \\
\hline $\begin{array}{l}\text { Causing death by careless driving while over the } \\
\text { alcohol limit }\end{array}$ & 3.512 & 0.182 & $<0.001$ \\
\hline Causing serious injury by dangerous driving & 4.238 & 0.205 & $<0.001$ \\
\hline Kidnap & 3.568 & 0.137 & $<0.001$ \\
\hline Conspiracy to kidnap & 3.57 & 0.275 & $<0.001$ \\
\hline Restraint of person's freedom of movement & 3.683 & 0.118 & $<0.001$ \\
\hline
\end{tabular}


PINA-SÁNCHEZ ET AL.

TABle 2 Continued

\begin{tabular}{lccc}
\hline Variable & Coefficient & Standard error & $P$ value \\
\hline$\quad$ Collecting a record of information to commit acts of & 4.693 & 0.175 & $<0.001$ \\
$\quad \begin{array}{l}\text { terrorism } \\
\quad \text { Engaging in conduct in preparation for acts of terrorism }\end{array}$ & 3.328 & 0.161 & $<0.001$ \\
Random effects & & & \\
$\quad$ Standard deviation random intercept & 0.184 & & \\
Sample size & & & \\
$\quad$ Level 1-case: $N=8,437$ & & & \\
$\quad$ Level 2-court: $N=86$ & & & \\
\hline
\end{tabular}

in the expected direction. For example, all offence types were associated with shorter sentences than the reference category, murder; so were cases where guilty plea was entered or cases featuring mitigating factors. On the other hand, cases where victim impact statements or public protection sentences were established, sentences were significantly longer. Finally, it may be argued that analyses based on our sample failed to capture a discrimination effect which only arises in response to terrorism offences. For this reason, we replicated the analyses using only cases containing a terrorism offence. In addition, the model presented in Table 2 was repeated including interaction effects for Muslim-name and the terrorism offences captured in our sample. None of those interaction terms were statistically significant, nor was the main effect for Muslim-name in any of the two additional models. Thus, we found no evidence of discrimination even in the specific cases where the main offence involved terrorism.

\section{Discussion}

Concerns about racial discrimination in sentencing have persisted for decades as seen in the immense body of research generated on the topic (Spohn 2000; Ulmer 2012; Baumer 2013). However, the vast majority of this research has emanated from the United States; the United Kingdom has lagged far behind. This oversight can to a degree be explained by the more pronounced racial tensions that have historically affected the United States. Yet recent incidents such as the raise in hate crime following the Brexit referendum (Burnett 2017; Cuerden and Rogers 2017), or Islamophobic episodes following the series of ISIS-inspired terrorist attacks that took place last year in London (Dodd and Marsh 2017), serve as a timely reminder of the racial and ethnic tensions permeating British society.

The necessary debate in the United Kingdom regarding the presence of discrimination in sentencing - and the criminal justice system more generally-has been revived with the publication of two important reports: the Lammy Review focusing on BAME defendants and the study of discrimination against Muslim offenders of terrorism undertaken by the Home Office. However, these studies have failed to rise to the challenge of testing for discrimination, in part as a result of their reluctance to undertake more refined multivariate analyses capable of distinguishing legitimate sentencing disparities from genuine discriminatory practices. The failure of the Ministry of Justice and the Home Office to disclose their sentencing and defendant records in full has also inhibited researchers and restricted the quantity and quality of literature on the topic. 
Paradoxically, if the official data had been shared publicly, these government agencies might have found that the research they were tasked to perform had already been undertaken by independent researchers.

Without access to official individual-level sentencing data including various defendant identities, we drew upon the application of data scraping and text mining techniques to a large sample of cases stored in an online legal database. We were then able to capture the specific type of offence-a variable that official research has failed to employ, which is nonetheless crucial to control for the offence seriousness-and a series of other legally relevant case characteristics. Our analyses found no evidence of discrimination against offenders with traditional Muslim names, whether the analysis included all offences or only terrorism-related crimes.

These findings should not be taken as conclusive proof of a lack of discrimination in sentencing against Muslim offenders; there is clearly a need for further research; most notably, our sample over-represents serious crimes. The principal contribution of our study lies in highlighting how the use of simple descriptive statistics in this area of research can be misleading. We initially showed that Muslim-named offenders received custodial sentences that were on average 9.8 per cent longer than those imposed to non-Muslim offenders, but we also demonstrated that this disparity was explained by legally relevant case characteristics. The fact that certain case characteristics are more concentrated on some minority groups should be a cause of concern, which deserves the attention of researchers and policymakers. For example, BAME defendants being less likely to plead guilty (Hood 1992; Thomas 2010) could reflect legitimate concerns arising from their interactions with the police (Bradford 2014), or lower levels of trust in the justice system (Jackson et al. 2010; Centre for Justice Innovation 2017). The key point, however, is that simple average differences between groups of offenders cannot be taken as evidence of discrimination at sentencing.

Independent of actual discrimination, the perception of discrimination in sentencing affects social cohesion and trust in the criminal justice system (Roberts and Plesničar 2015), which in turn may affect compliance with the law (Casper et al. 1988; Tyler et al. 1989; Hough et al. 2013). Whether discrimination in sentencing actually exists, it is clear that the system is perceived to be prone to this problem (Hood et al. 2003; Shute et al. 2005; Irwin-Rogers 2018). Claims of discrimination often arise following publication of the biannual Ministry of Justice Race Statistics Report (e.g. Wright 2013), equating differences in sentencing with discriminatory practice. The more recent Ministry publications (Hopkins 2015; Hopkins et al. 2016) are still limited since they control only for guilty plea, previous convictions and the broad crime category. Such studies fail to control for other important legally relevant case characteristics and can lead external observers to conclude that discrimination has been documented.

\section{Future research priorities}

After reviewing limited data that 'could not account for the impact of aggravating and mitigating factors or the possibility that BAME offenders may have been convicted of more serious drug offences than [White offenders]' (p. 33), the Lammy Review issued a challenge, stating that 'It is now incumbent on the judiciary to produce an

evidence-based explanation for the finding' (p. 33). The judiciary is not necessarily the 
only appropriate body capable to respond to this challenge. The Lammy Review has attracted the interest of experts from different disciplines in the United Kingdom and elsewhere. We believe that it would be wise to promote the engagement of academic researchers and in so doing exploit the cutting-edge methodological skills and substantive knowledge of the topic that they can offer. One way to do so would be to facilitate the sentencing data currently unpublished or published in a redacted form after censoring key variables.

The necessary data to carry out this research are available, although collected by different agencies, and not fully disclosed to non-government researchers. The Sentencing Council for England and Wales has been collecting samples of sentences from the Crown Court and the magistrates' courts with which to assess the impact of their guidelines. These data sets record in detail the legally relevant characteristics taken into account by the court in each case (Sentencing Council 2012; Pina-Sánchez 2015). For example, Pina-Sánchez and Grech (2018) were able to employ 52 case characteristics relevant to offences of assault captured in the Council's 'Crown Court Sentencing Survey' to isolate in unprecedented detail unwarranted from gross disparities in sentencing. The Sentencing Council data do not include the ethnicity of the defendant. However, it does capture the 'case number', the unique identifier used by HMCTS to track cases through the criminal justice system. Using this code, the Sentencing Council data could be linked to Ministry data that capture information on the ethnic background of the defendant.

An important research priority for the Ministry and the Council therefore is to link these two data sources with a view to conducting the necessary multivariate analyses in order to determine whether there is any evidence of ethnic discrimination in sentencing. If these public bodies prefer not to carry out this responsibility, they could provide the unique identifiers in the data sets they have released, so other non-government researchers can undertake this analysis. Until and unless answers based on a robust methodology are forthcoming, questions about the fairness of sentencing in England and Wales will persist.

It is worth underlining how such research would be able to provide the most robust findings on the topic of sentencing discrimination, not only in England and Wales, but also worldwide. As far as we are aware, never before has a data set like the 'Crown Court Sentencing Survey' been used for the study of discrimination in sentencing. In combination with the previously mentioned detail in recording case characteristics, this data set offers a vast sample size-roughly a quarter of a million of cases. The combination of these two features would make the findings from this research unmatched in terms of both internal and external validity.

Finally, in order to provide a comprehensive investigation of the presence of discrimination in sentencing, it is necessary to go beyond the sentence outcome to include all decisions taken before the final sentence is passed, such as the assessment of offence seriousness or determination of the level of guilty plea reduction (Pina-Sánchez et al. 2018). Furthermore, it is important to acknowledge that sentencing is just one of the multiple decisions involved in the criminal justice system. These analyses should also be extended to previous stages of the criminal justice system since they determine the cases being processed in court (Kalunta-Crumpton 1998; Baumer et al. 2000; Wooldredge 2012; Baumer 2013; Spohn et al. 2017). Studies that have used a more encompassing view of the criminal justice system have pointed at the first elements of the process (stop 
and search, arrests etc.) as the most problematic in terms of differences in treatment (Crow 1987; Delsol and Shiner 2006).

\section{Data scraping and text mining online sentencing records}

We end this article by highlighting the many research avenues that data scraping and text mining techniques offer to the study of sentencing. Similar techniques have been implemented before for the classification of legal cases (Evans et al. 2007; Alschner and Skougarevskiy 2016), but not for the generation of a data set covering the main factual elements of sentencing records. Until government agencies disclose their official records fully, the scraping of alternative sentencing archives offers a new research approach to questions that have been insufficiently explored. For example, besides the offender's name, 'The Law Pages' archive includes additional information normally unavailable in large-scale data sets, such as the name of the judge who imposed the sentence, the court location, the name of the defendant's advocate, the number of offences featuring in the sentence and summary excerpts of the verdict.

Using this data, new analyses could focus on (1) consistency in sentencing, a research question that in the United Kingdom has relied predominantly on the measurement of between court/area disparities (Tarling 2006; Mason et al. 2007; Pina-Sánchez and Linacre 2013; Pina-Sánchez 2015; Pina-Sánchez et al. 2016; 2018; Pina-Sánchez and Grech 2018), at the expense of neglecting disparities occurring at the between judge level (Pina-Sánchez and Linacre 2016); (2) court-judge interactions to explore questions such as, how does judicial rotation across courts affect the sentencing practice? (Hester 2017); (3) the effect of legal representation (Bright 1994; Lu and Miethe 2002); (4) the application of the 'totality' principle, which applies to sentencing of multiple offences (Vibla 2015; Ryberg et al. 2017); or (5) how judges employ controversial sentencing factors such as the offence committed while under the influence of alcohol (Dingwall and Koffman 2008; Padfield 2011). We cannot share the data that we have used without infringing copyright, ${ }^{15}$ but we encourage other researchers to follow our approach to investigate these-and other-questions that to date have been constrained by the limitations affecting official sentence data.

\section{Acknowledgements}

We thank Charles Oppenheim and Jane Secker for their invaluable support and advice concerning the legal and methodological challenges associated with the text data mining process undertaken in this research. We also want to extend our thanks to Alpa Parmar, Keir Irwin Rogers, Graham Farrell, Sam Lewis and Ian Marder for their assistance and comments on earlier drafts of this manuscript.

\section{REFERENCES}

Alschner, W. and Skougarevskiy, D. (2016), 'Mapping the Universe of International Investment Agreements', Journal of International Economic Law, 19: 561-88.

\footnotetext{
${ }^{15} \mathrm{We}$ can however share the code used to generate the data scraping algorithm upon request.
} 
PINA-SÁNCHEZ ET AL.

Anderson, D. (2012), 'The Terrorism Acts in 2011. Report of the Independent Reviewer on the Operation of the Terrorism Act 2000 and Part 1 of the Terrorism Act 2006', HMSO, available online at https://assets.publishing.service.gov.uk/government/uploads/system/uploads/attachment_data/file/228552/9780108511769.pdf.

Anderson, J., Kling, J. and Stith, K. (1999), 'Measuring Inter-judge Sentencing Disparity: Before and After the Federal Sentencing Guidelines', The Journal of Law and Economics, 42: 271-307.

Ashworth, A. (2010), Sentencing and Criminal Justice. Cambridge University Press.

Baumer, E. P. (2013), 'Reassessing and Redirecting Research on Race and Sentencing', Justice Quarterly, 30: 231-61.

Baumer, E. P., Messner, S. F. and Felson, R. B. (2000), 'The Role of Victim Characteristics in the Disposition of Murder Cases', Justice Quarterly, 17: 281-308.

Belton, I. (2018), 'The Role of Personal Mitigating Factors in Criminal Sentencing Judgments: An Empirical Investigation', doctoral dissertation, Middlesex University.

Bouwhuis, C. B. and Moll, H. A. (2003), 'Determination of Ethnicity in Children in the Netherlands: Two Methods Compared', European Journal of Epidemiology, 18: 385-8.

Bradford, B. (2014), 'Policing and Social Identity: Procedural Justice, Inclusion and Cooperation between Police and Public', Policing and Society, 24: 22-43.

Brantingham, P. (1985), 'Sentencing Disparity: An Analysis of Judicial Consistency', Journal of Quantitative Criminology, 1: 281-305.

Bright, S. B. (1994), 'Counsel for the Poor: The Death Sentence Not for the Worst Crime but for the Worst Lawyer', The Yale Law Journal, 103: 1835-83.

Brown, I. and Hullin, R. (1992), 'A Study of Sentencing in the Leeds Magistrates' Courts: The Treatment of Ethnic Minority and White Offenders', British Journal of Criminology, 32: 41-53.

Burnett, J. (2017), 'Racial Violence and the Brexit State', Race and Class, 58: 85-97.

Bushway, S. and Piehl, A. (2001), 'Judging Judicial Discretion: Legal Factors and Racial Discrimination in Sentencing', Law and Society Review, 35: 733-67.

Casper, J. D., Tyler, T. and Fisher, B. (1988), 'Procedural Justice in Felony Cases', Law and Society Review, 22: 483-507.

Centre for Justice Innovation (2017), 'Building Trust: How our Courts Can Improve the Criminal Court Experience for Black, Asian, and Minority Ethnic Defendants', available online at http://justiceinnovation.org/wp-content/uploads/2017/03/BuildingTrust.pdf.

Chigwada-Bailey, R. (2003), Black Women's Experiences of Criminal Justice: Race, Gender and Class: A Discourse on Disadvantage. Waterside Press.

Cole, B. and Wardak, A. (2006), 'Black and Asian Men on Probation: Social Exclusion, Discrimination and Experiences of Criminal Justice', in S. Lewis, P. Raynor, D. Smith and A. Wardak, eds, Race and Probation, 81-99. Willan.

Cox, D. R. (1975), 'Partial Likelihood', Biometrika, 62: 269-76.

Crow, I. (1987), 'Black People and Criminal Justice in the UK', The Howard Journal, 26 : 303-14.

Cuerden, G. and Rogers, C. (2017), 'Exploring Race Hate Crime Reporting in Wales Following Brexit', Review of European Studies, 9: 158-64.

Cummins, C., Winter, H., Cheng, K. K., Maric, R., Silcocks, P. and Varghese, C. (1999), 'An Assessment of the Nam Pehchan Computer Program for the Identification of Names of South Asian Ethnic Origin', Journal of Public Health Medicine, 2: 401-6. 
Delsol, R. and Shiner, M. (2006), 'Regulating Stop and Search: A Challenge for Police and Community Relations in England and Wales', Critical Criminology, 14: 241-63.

Dingwall, G. and Koffman, L. (2008), 'Determining the Impact of Intoxication in a Desert-Based Sentencing Framework', Criminology and Criminal Justice, 8: 335-48.

Dodd,V.andMarsh,S. (2017), 'Anti-MuslimHateCrimesIncreaseFivefoldsinceLondonBridge Attacks', The Guardian, available online at https://www.theguardian.com/uk-news/2017/ jun/07/anti-muslim-hate-crimes-increase-fivefold-since-london-bridge-attacks.

EArle, R. (2011), 'Ethnicity, Multiculture and Racism in a Young Offenders' Institution', Prison Service Journal, 197: 32-8.

Evans, M., McIntosh, W., Lin, J. and Cates, C. (2007), 'Recounting the Courts? Applying Automated Content Analysis to Enhance Empirical Legal Research', Journal of Empirical Legal Studies, 4: 1007-39.

Everett, R. S. and Wojtkiewicz, R. A. (2002), 'Difference, Disparity, and Race/Ethnic Bias in Federal Sentencing', Journal of Quantitative Criminology, 18: 189-211.

Feilzer, M. and Hood, R. (2004), Differences or Discrimination: Minority Ethnic Young People in the Youth Justice System. Youth Justice Board.

Feldmeyer, B. and Ulmer, J. T. (2011), 'Racial/Ethnic Threat and Federal Sentencing', Journal of Research in Crime and Delinquency, 48: 238-70.

Fischman, J. B. and Schanzenbach, M. M. (2012), 'Racial Disparities under the Federal Sentencing Guidelines: The Role of Judicial Discretion and Mandatory Minimums', Journal of Empirical Legal Studies, 9: 729-64.

Green, E. (1961), Judicial Attitudes in Sentencing: A Study of the Factors Underlying the Sentencing Practice of the Criminal Court of Philadelphia. Macmillan.

Hall, E. L. and Simkus, A. A. (1975), 'Inequality in the Types of Sentences Received by Native Americans and Whites', Criminology, 13: 199-222.

Hester, R. (2017), 'Judicial Rotation as Centripetal Force: Sentencing in the Court Communities of South Carolina', Criminology, 55: 205-35.

Hofer, P. J., Blackwell, K. and Ruback, R. B. (1999), 'The Effect of the Federal Sentencing Guidelines on Inter-judge Sentencing Disparity', Journal of Criminal Law and Criminology, 90: 239-21.

Home Office (2013), 'Terrorism Arrests - Analysis of Charging and Sentencing Outcomes by Religion', OSCT Counter Terrorism Research and Analysis, available online at https://www.gov.uk/government/publications/terrorism-arrests-analysis-of-charging-and-sentencing-outcomes-by-religion/ terrorism-arrests-analysis-of-charging-and-sentencing-outcomes-by-religion.

Hood, R. G. (1992), Race and Sentencing: A Study in the Crown Court: A Report for the Commission for Racial Equality. Oxford University Press.

Hood, R., Shute, S. and Seemungal, F. (2003), Ethnic Minorities in the Criminal Courts: Perceptions of Fairness and Equality of Treatment. Lord Chancellor's Department.

Hopkins, K. (2015), 'Associations between Police-Recorded Ethnic Background and Being Sentenced to Prison in England and Wales', Ministry of Justice, available online at https://assets.publishing.service.gov.uk/government/uploads/system/uploads/attachment_data/file/479874/analysis-of-ethnicity-and-custodial-sentences.pdf.

Hopkins, K., Uhrig, N. and Colahan, M. (2016), 'Associations between Ethnic Background and Being Sentenced to Prison in the Crown Court in England and Wales in 2015, Ministry of Justice, available online at https:// www.insidetime.org/download/research_\&_reports/ministry_of_justice/ 
associations-between-ethnic-background-being-sentenced-to-prison-in-the-crown-courtin-england-and-wales-2015.pdf.

Hough, M., Bradford, B., Jackson, J. and Roberts, J. V. (2013), 'Attitudes to Sentencing and Trust in Justice: Exploring Trends from the Crime Survey for England and Wales', Ministry of Justice Analytical Series, Ministry of Justice, available online at https://www. gov.uk/government/uploads/system/uploads/attachment_data/file/230186/Attitudes_ to_Sentencing_and_Trust_in_Justice__web_.pdf.

Irwin-Rogers, K. (2018), 'Racism and Racial Discrimination in the Criminal Justice System: Exploring the Views of Men Serving Sentences of Imprisonment', Justice, Power, Resistance, 2: 243-66.

Irwin-Rogers, K. and Perry, T. H. (2015), 'Exploring the Impact of Sentencing Factors on Sentencing Domestic Burglary', in J. V. Roberts, ed., Sentencing Guidelines: Exploring Sentencing Practice in England and Wales, 213-39. Palgrave Macmillan.

Jackson, J., Tyler, T. R., Bradford, B., Taylor, F. and Shiner, M. (2010), 'Legitimacy and Procedural Justice in Prisons', Prison Service Journal, 191: 4-10.

Jacobson, J., Kirby, A. and Hunter, G. (2016), 'Joint Enterprise: Righting a Wrong Turn? Report of an Exploratory Study', Prison Reform Trust, available online at http://www. prisonreformtrust.org.uk/Portals/0/Documents/Joint\%20Enterprise\%20Writing\%20 a\%20Wrong\%20Turn.pdf.

Johnson, B. D. (2005), 'Contextual Disparities in Guidelines Departures: Courtroom Social Contexts, Guidelines Compliance, and Extralegal Disparities in Criminal Sentencing', Criminology, 43: 761-96.

Kalunta-Crumpton, A. (1998), 'The Prosecution and Defence of Black Defendants in Drug Trials', British Journal of Criminology, 38: 561-91.

King, D. K. and Johnson, B. D. (2016), 'A Punishing Look: Skin Tone and Afrocentric Features in the Halls of Justice', American Journal of Sociology, 122: 90-124.

Lammy, D. (2017), 'An Independent Review into the Treatment of, and Outcomes for, Black, Asian and Minority Ethnic Individuals in the Criminal Justice System', HMSO, available online at https://assets.publishing.service.gov.uk/government/uploads/system/uploads/ attachment_data/file/643001/lammy-review-final-report.pdf.

Lavorgna, A. (2015), 'The Online Trade in Counterfeit Pharmaceuticals: New Criminal Opportunities, Trends and Challenges', European Journal of Criminology, 12: 226-41.

Lightowlers, C. (2019), 'Drunk and Doubly Deviant? The Role of Gender and Intoxication in Sentencing Assault Offences', British Journal of Criminology, 59: 693-717.

Lightowlers, C. and Pina-SÁnchez, J. (2017), 'Intoxication and Assault: An Analysis of Crown Court Sentencing Practices in England and Wales', British Journal of Criminology, 58: $132-54$.

Lu, H. and Miethe, T. D. (2002), 'Legal Representation and Criminal Processing in China', British Journal of Criminology, 42: 267-80.

Mason, T., De Silva, N., Sharma, N., Brown, D. and Harper, G. (2007), 'Local Variation in Sentencing in England and Wales', Ministry of Justice, available online at https:// assets.publishing.service.gov.uk/government/uploads/system/uploads/attachment_ data/file/217971/local-variation-sentencing-1207.pdf.

Mateos, P. (2007), 'A Review of Name-Based Ethnicity Classification Methods and their Potential in Population Studies', Population, Space and Place, 13: 243-63. 
May, T., Gyateng, T. and Hough, M. (2010), 'Differential Treatment in the Youth Justice System', Equality and Human Rights Commission, available online at https://www.equalityhumanrights.com/sites/default/files/differential_treatment_in_the_youth_justice_ system_final.pdf.

Ministry of Justice (2017), 'Statistics on Race and the Criminal Justice System 2016', HMSO, available online at https://assets.publishing.service.gov.uk/ government/uploads/system/uploads/attachment_data/file/669094/ statistics_on_race_and_the_criminal_justice_system_2016_v2.pdf.

Nanchahal, K., Mangtani, P., Alston, M. and Dos Santos Silva, I. (2001), 'Development and Validation of a Computerized South Asian Names and Group Recognition Algorithm (SANGRA) for Use in British Health-Related Studies', Journal of Public Health Medicine, 23: 278-85.

Padfield, N. (2011), 'Intoxication as a Sentencing Factor: Mitigation or Aggravation', in J. V. Roberts, ed., Mitigation and Aggravating at Sentencing, 81-101. Cambridge University Press.

Pantazis, C. and Pemberton, S. (2009), 'From the "Old" to the "New" Suspect Community: Examining the Impacts of Recent UK Counter-terrorist Legislation', British Journal of Criminology, 49: 646-66.

Phillips, C. (2012), The Multicultural Prison: Ethnicity, Masculinity, and Social Relations among Prisoners. Oxford University Press.

Phillips, C. and Bowling, B. (2017), 'Ethnicities, Racism, Crime and Criminal Justice', in A. Liebling, S. Maruna and L. McAra, eds, The Oxford Handbook of Criminology. Oxford University Press.

Pina-SÁnchez, J. (2015), 'Defining and Measuring Consistency in Sentencing', in J. V. Roberts, ed., Sentencing Guidelines: Exploring Sentencing Practice in England and Wales, 7692. Palgrave Macmillan.

Pina-SÁnchez, J., Brunton-Smith, I. and Guangquan, L. (2018), 'Mind the Step: A More Insightful and Robust Analysis of the Sentencing Process in England and Wales under the New Sentencing Guidelines', Criminology and Criminal Justice.

Pina-Sánchez, J. and Grech, D. C. (2018), 'Location and Sentencing: To What Extent Do Contextual Factors Explain between Court Disparities?’, British Journal of Criminology, 58: 529-49.

Pina-Sánchez, J., Lightowlers, C. and Roberts, J.V. (2016), 'Exploring the Punitive Surge: Crown Court Sentencing Practices Before and After the 2011 English Riots', Criminology and Criminal Justice, 17: 319-39.

Pina-SÁnchez, J. and Linacre, R. (2013), 'Sentence Consistency in England and Wales: Evidence from the Crown Court Sentencing Survey', British Journal of Criminology, 53: $1118-38$.

- (2014), 'Enhancing Consistency in Sentencing: Exploring the Effects of Guidelines in England and Wales', Journal of Quantitative Criminology, 30: 731-48.

- (2016), 'Refining the Measurement of Consistency in Sentencing: A Methodological Review', International Journal of Law, Crime and Justice, 44: 68-87.

Raynor, P. and Lewis, S. (2011), 'Risk-Need Assessment, Sentencing and Minority Ethnic Offenders in Britain', British Journal of Social Work, 41: 1357-71.

Roberts, J. V. and Plesničar, M. (2015), 'Sentencing, Legitimacy, and Public Opinion', in G. Meško and J. Tankebe, eds, Trust and Legitimacy in Criminal Justice, 33-51. Springer International Publishing. 
PINA-SÁNCHEZ ET AL.

Ryberg, J., Roberts, J. V. and de Keijser, J. (eds) (2017), Sentencing Multiple Crimes. Studies in Penal Theory and Philosophy. Oxford University Press.

Saperstein, A. (2006), 'Double-Checking the Race Box: Examining Inconsistency between Survey Measures of Observed and Self-reported Race', Social Forces, 85: 57-74.

Sentencing Council (2012), 'Crown Court Sentencing Survey: Annual Publication, 2011', available online at https://www.sentencingcouncil.org.uk/wp-content/uploads/CCSS_ Annual_2011.pdf.

Shute, S., Hood, R. and Seemungal, F. (2005), A Fair Hearing? Ethnic Minorities in the Criminal Courts. Willan.

Spohn, C. (2000), 'Thirty Years of Sentencing Reform: The Quest for a Racially Neutral Sentencing Process', in W. Reed and L. Winterfield, eds, Criminal Justice 2000, Volume 3: Policies, Processes, and Decisions of the Criminal Justice System, 427-502. US Department of Justice.

Spohn, C., Brennan, P. K. and Kim, B. (2017), 'Explicating the Patterns of Disparities Using a Path Model', in J. T. Ulmer and M. S. Bradley, eds, Handbook on Punishment Decisions: Locations of Disparity, 211-38. Routledge.

TARling, R. (2006), 'Sentencing Practice in Magistrates' Courts Revisited', Howard Journal, 45: 29-41.

The Secret Barrister (2018), Stories of the Law and How It's Broken. MacMillan.

Therneau, T. (2015), 'A Package for Survival Analysis in S, Version 2.38', available online at https://CRAN.R-project.org/package=survival.

— (2018), 'Mixed Effects Cox Models', Mayo Clinic Working Paper, available online at https://cran.r-project.org/web/packages/coxme/vignettes/coxme.pdf.

Thomas, C. (2010), 'Are Juries Fair?', Ministry of Justice, available online at https://www. justice.gov.uk/downloads/publications/research-and-analysis/moj-research/are-juriesfair-research.pdf.

Tyler, T. R., Casper, J. D. and Fisher, B. (1989), 'Maintaining Allegiance toward Political Authorities: The Role of Prior Attitudes and the Use of Fair Procedures', American Journal of Political Science, 33: 629-52.

Ulmer, J. T. (2012), 'Recent Developments and New Directions in Sentencing Research', Justice Quarterly, 29: 1-40.

Vibla, N. (2015), 'More than One Crime: Sentencing the Multiple Conviction Offender', in J. V. Roberts, ed., Sentencing Guidelines: Exploring Sentencing Practice in England and Wales, 221-34. Palgrave Macmillan.

Waldfogel, J. (1998), 'Does Inter-judge Disparity Justify Empirically Based Sentencing Guidelines?', International Review of Law and Economics, 18: 293-304.

Wooldredge, J. (2012), 'Distinguishing Race Effects on Pre-trial Release and Sentencing Decisions', Justice Quarterly, 29: 41-75.

Wright, O. (2013), “'Courts Are Biased against Blacks” with White Offenders Handed more Lenient Sentences, Says Official Report', The Independent, available online at https://www. independent.co.uk/news/uk/crime/courts-are-biased-against-blacks-with-white-offenders-less-likely-to-be-jailed-for-similar-crimes-8959804.html.

Zatz, M. S. (1987), 'The Changing Forms of Racial/Ethnic Bias in Sentencing', Journal of Research in Crime and Delinquency, 24: 69-92. 